\title{
Synthesis, Kinetics and Mechanism of Terpolymerization of Styrene, Vinyl Acetate with Acrylonitrile Initiated by P-Nitrobenzyl Triphenyl Phosphonium Ylide
}

\author{
Kiran Prajapati, Anuradha Varshney* \\ Chemistry Department, D. G. College, Kanpur, India \\ E-mail: varshney_anuradha@rediffmail.com \\ Received April 1, 2011; revised May 17, 2011; accepted May 28, 2011
}

\begin{abstract}
Synthesis of terpolymers consisting of two electron-donating monomers, viz. styrene and vinyl acetate with one electron-accepting monomer, i.e. acrylonitrile, initiated by p-nitrobenzyl triphenyl phosphonim ylide in dioxane as diluent at $65^{\circ} \mathrm{C}$ for $150 \mathrm{~min}$ has been studied. The kinetic expression is $R_{p} \alpha[\mathrm{I}]^{0.8}[S t y]^{1.2}[V A]^{1.4}[A N]^{1.2}$. The terpolymer composition was determined by the Kelen-Tüdos method. The values of reactivity ratios using $r_{1}(\mathrm{Sty}+\mathrm{VA})=0.1$ and $r_{2}(\mathrm{AN})=0.005$. The overall activation energy is $46 \mathrm{~kJ} \mathrm{~mol} \mathrm{~L}^{-1}$. The formation of terpolymer is confirmed by the FTIR spectra showing bands at $3030 \mathrm{~cm}^{-1}, 1598 \mathrm{~cm}^{-1}$, and $2362 \mathrm{~cm}^{-1}$, confirming the presence of phenyl, acetoxy and nitrile group respectively. The terpolymer has been characterized by ${ }^{1} \mathrm{H}$-Nuclear Magnetic Resonance, ${ }^{13} \mathrm{C}$-Nuclear Magnetic Resonance. The Differential Scanning Calorimetric curve shows the $T_{g}$ of the polymer as $149.5^{\circ} \mathrm{C}$. A scanning electron microscope confirms the polymer to be phosphorus free. Electron.Spin.Resonance spectra confirms phenyl radical responsible for initiation.
\end{abstract}

Keywords: P-Nitrobenzyltriphenyl Phosphonium Ylide (P-NBTPY), Terpolymer, Kinetics, Mechanism

\section{Introduction}

The interest in macromolecular architecture has increased dramatically in recent years. Terpolymerization, i.e. three component polymers has continued to attract the attention of both academics and industrialists due to their unique properties and potential application. One of the main advantages of this technique is that it allows information to be obtained on a class of monomers which is otherwise not available. Although voluminous literature is available for homo, and copolymerization very little kinetic and synthetic information is available for terpolymerization. This is due to wide variation in monomer reactivity with radicals and difficulty of simultaneous polymerization of three monomers together. A search of literature reveals that few terpolymer systems have been reported i.e., (styrene-acrylonitrileChromium acrylate)) and (styrene-Methyl meth acrylate-acrylonitrile) initiated by styrene arsenic sulfide complex [1-2] and (citronellol-styrene-methyl methacrylate) initiated by benzylperoxide[3], (styrene-acryloni- trile-copper acrylate) initiated by p-Acetyl benzylidene triphenyl arsoniumylide[4]. Recently, Zhang [5] prepared gradient polymer by complex radical terpolymerization of styrene, maleic anhydride and $\mathrm{N}$-vinyl pyrrolidone via gamma ray irradiation and Lodge[6] synthesized Three poly(ethylene-alt-propylene)-b-poly (ethyleneoxide)-bpoly(N-opropylacrylamide) (PEP-PEO-PNIPAm, "PON") triblock terpolymers using a combination of anionic and reversible addition-fragmentation chain transfer polymerization, and their micellization and micellar aggregation properties in dilute aqueous solution by dynamic light scattering (DLS) and cryo-TEM. An ylide is substance in which a carbanion is attached directly to a heteroatom carrying high degree of positive charge represented by the general formula I :

$$
\bigoplus_{>\mathrm{C}-\mathrm{X}<} \underset{0}{\oplus}
$$

Wittig reaction, a novel method for conversion of carbonyl group into olefinic functions has altered the role of ylide, moving them from the realm of chemical curiosi- 
ties into the arsenal of important synthetic tools.

The special characteristic of ylides that make them worthy of study in their own right is the unique stabilization afforded by the carbanions by the presence of the adjacent onium atom groups. Ylides have wide application [7] as reaction intermediate, synthetic and organic chemistry, and polymerization catalyst. Ylides with heteroatom, bismuth, nitrogen, sulphur, arsenic, antimony are also reported as initiators [8], retarders [9], degradative transfer agents [10] in the polymerization vinyl monomers. The application of phosphorus ylide in domain of polymer science is scarce [11-13].

Phosphorous ylide are reactive and unless special structural features, have been incorporated and are usually not capable of isolation. The sufficient stability of the phosphorus ylide to be capable of isolation has been attributed to the structural and electronic factors which contribute to stabilization of the ylidic carbonion. This stabilization has been thought to results from delocalization of the non-bonded electrons of the carbanion. In a given ylide, $\mathrm{X}-\mathrm{CR}_{2}$, stabilization for the carbanion could be afforded by both the heteroatom portion $(\mathrm{X})$ and the two carbanion substituents (R). The ability of the groups $\mathrm{R}$ to delocalize the carbanionic electrons does affect the stability of the ylide. However, it is equally apparent that this stabilization is not sufficient in itself to account for the unique stability of phosphorus ylides. The phosphorus atom itself must play an important role in the stabilization of the carbanion. The stabilization has been attributed to the use of the vacant $3 \mathrm{~d}$-orbitals of the phosphorus atom, the carbanion taking advantage of the ability of the phosphorus atom to expand its Outer shell to accommodate more than eight electrons. The pП-d $\Pi$ bonding in phosphorus ylide is controversial regarding structure and bonding [14].

Because of lack of data for the radical polymerization of Sty, AN, VA, it is very interesting to investigate its terpolymerization in the sequence of our continuing work [15]. Therefore, attempts have been made to synthesis the terpolymer and study the kinetics and characterization of the terpolymer initiated by p-nitrobenzyltriphenyl phosphonium ylide.

\section{Experimental}

\subsection{Materials}

Styrene (Sty), vinyl acetate (VA) and acrylonitrile (AN) (Merck) were washed with 4\% sodium hydroxide and distilled water [16]. The dried monomers were then distilled under reduced pressure. Triphenyl phospine (Merck) was used as received. P-nitrobenzyl triphenyl phosphnium ylide (p-NBTPY) was prepared by the method reported by McDonald and Campbell as reported in our earlier issue [11].

Briefly the synthesis of ylide is as follows: (Scheme 1)

\subsection{Characterization of P-Nitrobenzyltriphenyl Phosphonium Bromide}

1) M. P. $-275^{\circ} \mathrm{C}$

2) Elemental analysis -

Analysis calculated for $\mathrm{C}_{25} \mathrm{H}_{21} \mathrm{NO}_{2} \mathrm{Br}$ :

C, 63.0; H, 4.0; N, 2.93

Found: C, 62.6; H, 4.2; N, 3.14

3) FTIR (KBr) (Figure 1)

Aromatic $\mathrm{C}-\mathrm{H}$ stretching $3050 \mathrm{~cm}^{-1}$

(1)

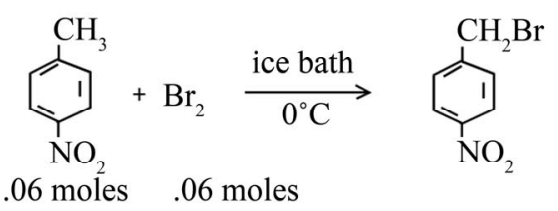

(2)

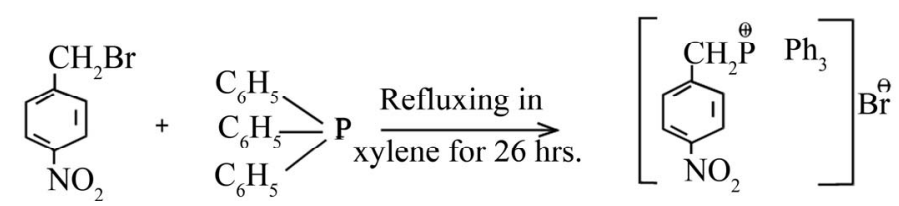

.04 moles

.04 moles

(3)

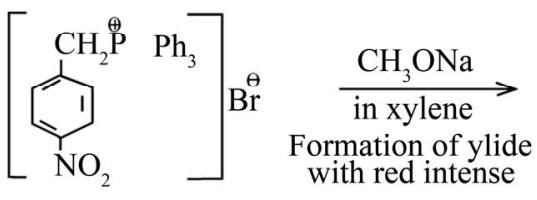

M.P. $=275^{\circ} \mathrm{C}$ yield $27 \%$<smiles>[CH]c1ccc(N=[Pb])cc1</smiles>

Scheme 1 
Aromatic $\mathrm{C}=\mathrm{C}$ stretching $1483 \mathrm{~cm}^{-1}$

A symmetric $\left(\mathrm{ArNO}_{2}\right) 1517 \mathrm{~cm}^{-1}$

Symmetric $\left(\mathrm{ArNO}_{2}\right) 1344 \mathrm{~cm}^{-1}$

ArNO2, C - N stretching $850 \mathrm{~cm}^{-1}$

$\mathrm{C}-\mathrm{Br}$ stretching $540 \mathrm{~cm}^{-1}$

4) $1 \mathrm{H}-\mathrm{NMR}$ (Figure 2)

$\left(2 \mathrm{H}-\mathrm{P}^{+}-\mathrm{CH}_{2}\right)$ Singlet at $3.4 \delta \mathrm{ppm}$

Multiplet of $19 \mathrm{H}$, Aromatic $7.68-7.85 \delta \mathrm{ppm}$.

\subsection{Terpolymerization}

The terpolymerization runs were carried out in a dilatometer $($ dia $=2 \mathrm{~mm}$, length $=10 \mathrm{~cm}$, capacity $=3 \mathrm{ml})$. The polymerization solution was prepared by taking requistic quantities of all the three monomers, alongwith. p-nitrobenzyl triphenyl phosphnium ylide (pNBTPY) in dioxane as an inert solvent. The polymerization was carried out for $150 \mathrm{~min}$ at $65^{\circ} \mathrm{C} \pm 1^{\circ} \mathrm{C}$ under nitrogen blanket. The terpolymer was precipitated with methanol. The terpolymer formed was refluxed with solvents, benzene, tetrahyrofuran and dimethylformamide to remove homo and copolymers. The weight loss in each refluxing was negligible. The rate of polymerization $\left(R_{p}\right)$ was calculated from the slope of the conversion versus time plots [17].

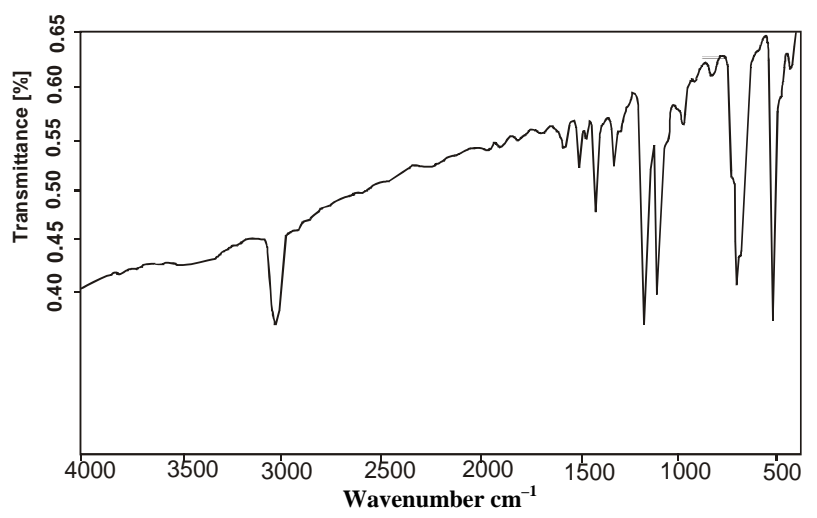

Figure 1. FTIR spectrum of p-nitrobenzyl triphenyl phosphonium bromide.

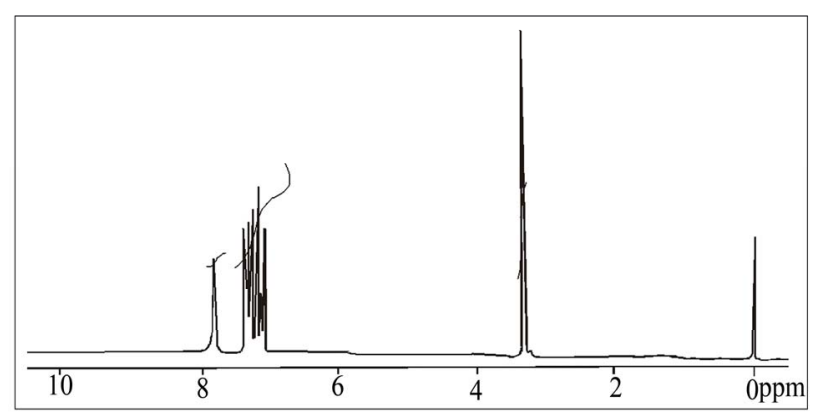

Figure 2. ${ }^{1} \mathrm{H}$-NMR spectrum of p-nitrobenzyl triphenyl phosphonium bromide.

\subsection{Characterization}

Fourier Transform Infrared Spectroscopy: FTIR spectra were recorded with Perkin-Elmer 599B in Dichloromethane. NMR Spectroscopy: ${ }^{1} \mathrm{H}-\mathrm{NMR}$ and ${ }^{13} \mathrm{C}-\mathrm{NMR}$ spectra were recorded with a Varian 100HA Jeol LA 400 spectrometer by using $\mathrm{CDCl}^{3}$ as solvent and tetramethyl silane as internal reference. DSC Analysis: were carried out by using Perkin-Elmer; Pyris Diamond differential scanning calorimetry; sample weight $2.43 \mathrm{mg}$ at heating rate $10^{\circ} \mathrm{C}$ and temperature range $0^{\circ} \mathrm{C}-500^{\circ} \mathrm{C}$. SEM Analysis was conducted in Jeol JSM 840 A scanning electron microscope. Sample was mounted on a brass stub using an adhesive and were gold coated. GPC: The GPC studies were made with a water 200 model using $\mathrm{THF}$ as a solvent at $25^{\circ} \mathrm{C}$. E.S.R Analysis was conducted in Brucker EMX E.S.R spectro-photometer, Model No-1444.

\section{Result and Discussion}

P-nitrobenzyl triphenyl phosphonium ylide initiated radical terpolymerization of styrene, vinylacetate and acrylonitrile. All the reactions are associated with induction period of about $2-16 \mathrm{~min}$. The conversion was restricted upto $16.3 \%$. The kinetics of terpolymerization was studied by varying. P-nitrobenzyl triphenyl phosphnium ylide (Figure 3) from $16.8 \times 10^{-6} \mathrm{~mol} \mathrm{~L}^{-1}$ to $51.3 \times$ $10^{-6} \mathrm{~mol} \mathrm{~L}^{-1}$, keeping [Sty] [VA] and [AN] constant at $1.44 \mathrm{~mol} \mathrm{~L}^{-1}, 1.44 \mathrm{~mol} \mathrm{~L}{ }^{-1}, 2.01 \mathrm{~mol} \mathrm{~L}^{-1}$ respectively. The effect of p-nitrobenzyl triphenyl phosphnium ylide on rate of polymerization $\left(R_{p}\right)$ is shown in Table 1 . The $R_{p}$ increases with increasing concentration of. p-nitrobenzyl triphenyl phosphnium ylide as expected for free radical terpolymerization. The order of reaction with respect to p-nitrobenzyl triphenyl phosphnium ylide is calculated from the slope of the plot of (Figure 4) $\log R_{p}$ versus $\log$ [p-NBTPY] is 0.8 .

The effect of monomer on the rate of polymerization is summarized in Table 2. The effect of [Sty] on Rp has been studied by varying [Sty] from $0.288 \mathrm{~mol} \mathrm{~L}^{-1}$ to 2.59 mol L ${ }^{-1}$, keeping ${ }^{-1}$ [VA], [AN] and [p-NBTPY] constant at $1.44 \mathrm{~mol} \mathrm{~L}^{-1}, 2.01 \mathrm{~mol} \mathrm{~L}^{-1}$ and $33.6 \times 10^{-1} \mathrm{~mol} \mathrm{~L}^{-1}$ respectively. A plot of $\log R_{p}$ and $\log$ [Sty] (Figure 5) is linear, the slope of which gives the relationship. Equation (1)

$$
R_{p} \alpha[S t y]^{1.2}
$$

The effect of [VA] on $R_{p}$ has been studied by varying [VA] from $0.72 \mathrm{~mol} \mathrm{~L}^{-1}$ to $2.88 \mathrm{~mol} \mathrm{~L}^{-1}$, keeping [Sty], [AN] and [p-NBTPY] constant at $1.44 \mathrm{~mol} \mathrm{~L}^{-1}, 2.01 \mathrm{~mol}$ $\mathrm{L}^{-1}$ and $33.6 \times 10^{-6} \mathrm{~mol} \mathrm{~L}^{-1}$ respectively. A plot of between $\log R_{p}$ and $\log$ [VA] (Figure 6) is linear, the slope of which gives the relationship: Equation (2) 


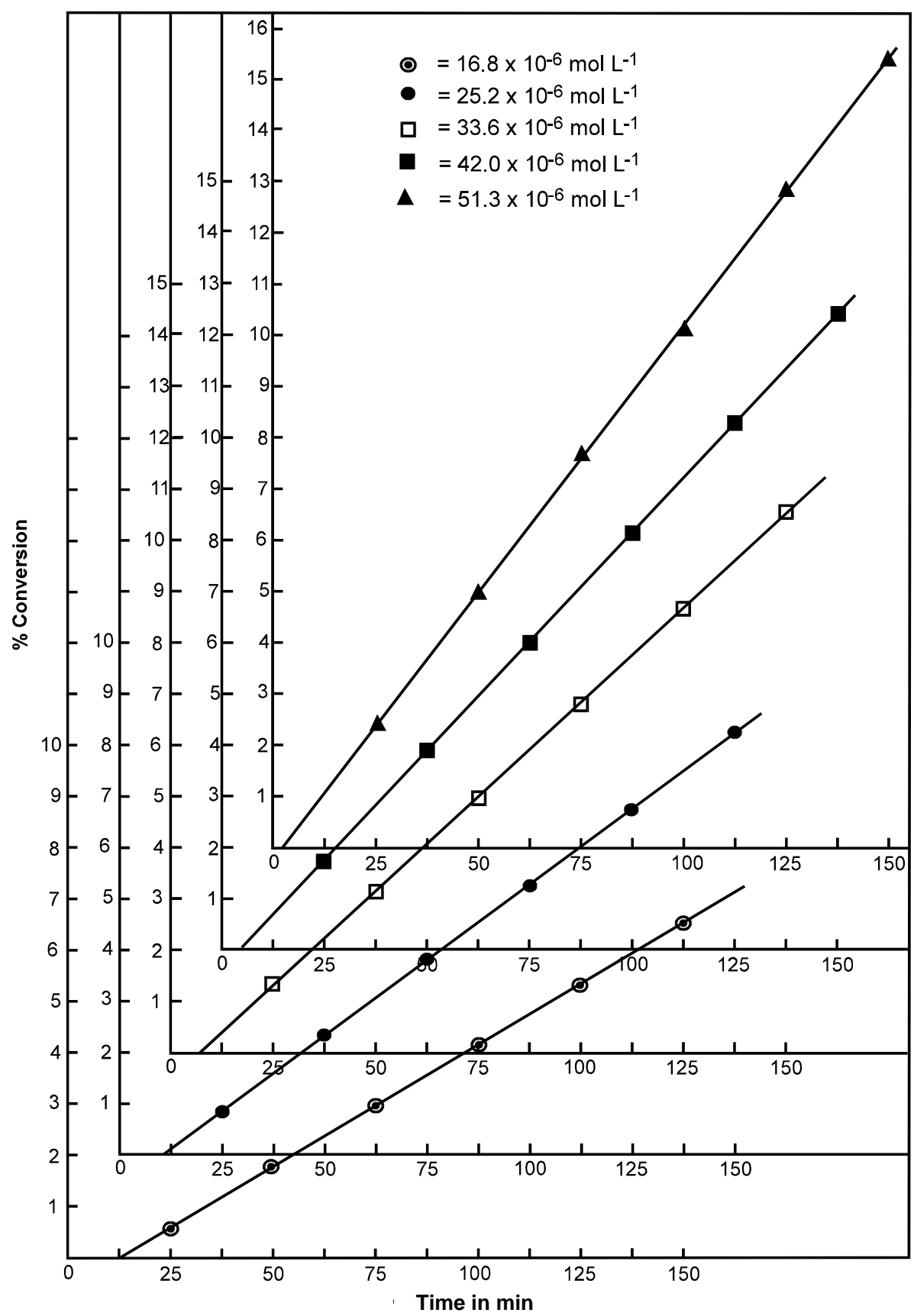

Figure 3. Time conversion profile in the ternary polymerization of Sty, VA, AN with [p-NBTPY] as radical initiator at $65^{\circ} \mathrm{C}$ in dioxane.

Table 1. Effect of [p-NBTPY] on the rate of terpolymerization.

\begin{tabular}{cccc}
\hline Sample No. & $\mathrm{p}$-NBTPY $\times 10^{-6} \mathrm{~mol}_{\mathrm{.}}-1$ & Percentage conversion & $R_{p} \times 10^{6} \mathrm{~mol}^{-1} \mathrm{~L}^{-1} \mathrm{~s}^{-1}$ \\
\hline 1. & 16.8 & 6.4 & 4.075 \\
2. & 25.2 & 8.2 & 4.89 \\
3. & 33.6 & 10.6 & 5.705 \\
4. & 42.0 & 12.4 & 7.335 \\
5. & 51.3 & 15.2 & 8.965 \\
\hline
\end{tabular}

$[$ Sty $]=1.44 \mathrm{~mol} \mathrm{~L}^{-1},[\mathrm{VA}]=1.44 \mathrm{~mol}, \mathrm{~L}^{-1}[\mathrm{AN}]=2.01 \mathrm{~mol} . \mathrm{L}^{-1} \mathrm{Time}=150 \mathrm{~min}$, Temperature $=65^{\circ} \mathrm{C} \pm 1^{\circ} \mathrm{C}$. 
Table 2. Effect of [monomers] on the rate of terpolymerization of (styrene-co-vinyl acetate-co-acrylonitrile) initiated by p-NBTPY.

\begin{tabular}{cccc}
\hline Sample No. & Monomers & Percentage conversion & $\begin{array}{c}R_{p} \times 10^{6} \\
\mathrm{~mol}^{-1} \mathrm{~L}^{-1} \mathrm{~s}^{-1}\end{array}$ \\
\hline $6[\mathrm{Sty}]^{*}$ & 0.28 & 7.02 & 3.11 \\
7 & 0.86 & 8.35 & 4.31 \\
8 & 2.01 & 13.9 & 9.1 \\
9 & 2.59 & 15.6 & 11.07 \\
$10[\mathrm{VA}]^{* *}$ & 0.72 & 9.1 & 4.17 \\
11 & 2.16 & 11.4 & 7.48 \\
12 & 2.88 & 14.3 & 11.60 \\
$13[\mathrm{AN}]^{* * *}$ & 1.00 & 5.6 & 2.58 \\
14 & 3.01 & 12.1 & 8.83 \\
15 & 4.02 & 15.7 & 11.50 \\
\hline
\end{tabular}

${ }^{*}[\mathrm{VA}]=1.44 \mathrm{~mol} \mathrm{~L}^{-1},[\mathrm{AN}]=2.01 \mathrm{~mol} . \mathrm{L}^{-1},(\mathrm{p}-\mathrm{NBTPY})=33.6 \times 10^{-6} \mathrm{~mol} \mathrm{~L}^{-1 * *}[\mathrm{Sty}]=1.44 \mathrm{~mol} \mathrm{~L}^{-1},[\mathrm{AN}]=2.01 \mathrm{~mol} \mathrm{~L} \mathrm{~L}^{-1},(\mathrm{p}-\mathrm{NBTPY})=33.6$ $\times 10^{-6} \mathrm{~mol} \mathrm{~L}^{-1 * *}[\mathrm{Sty}] 1.44 \mathrm{~mol} \mathrm{~L}^{-1},[\mathrm{VA}]=1.44 \mathrm{~mol} \mathrm{~L}^{-1},(\mathrm{p}-\mathrm{NBTPY})=33.6 \times 10^{-6}, \mathrm{~mol} \mathrm{~L}^{-1}$ Time $=150 \mathrm{~min}$, Temperature $=65^{\circ} \mathrm{C} \pm 1^{\circ} \mathrm{C}$.

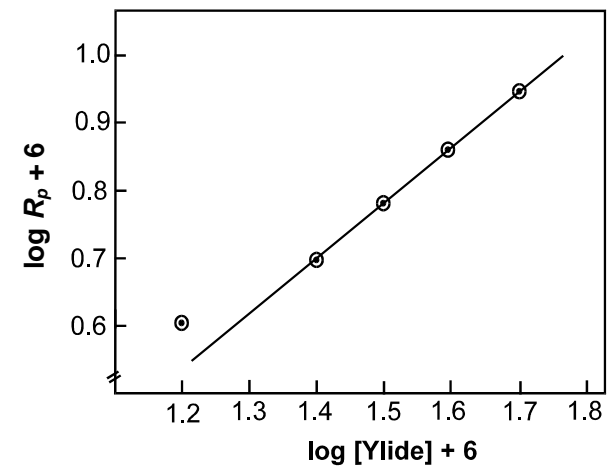

Figure 4. Plot for $\log R_{p}$ versus $\log [p-N B T P Y]$.

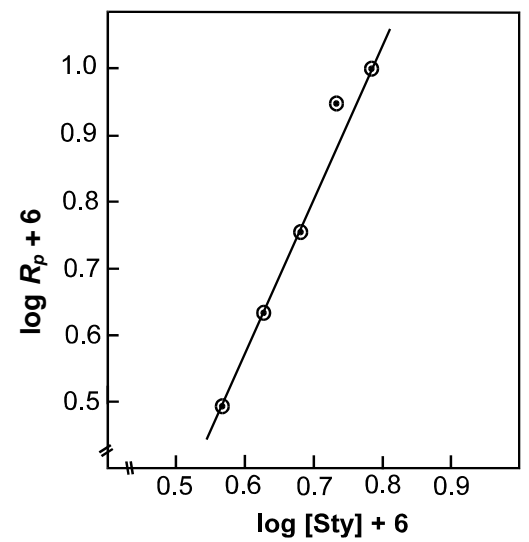

Figure 5. Plot of $\log R_{p}$ versus $\log$ [Sty].

$$
R_{p} \alpha[\mathrm{VA}]^{1.4}
$$

The effect of [AN] on Rp has been studied by varying [AN] from $1.00 \mathrm{~mol} \mathrm{~L}^{-1}$ to $4.02 \mathrm{~mol} \mathrm{~L}^{-1}$, keeping [Sty], [AN] and [p-NBTPY] constant at $1.44 \mathrm{~mol} \mathrm{~L}^{-1}, 1.44 \mathrm{~mol}$ $\mathrm{L}^{-1}$ and $33.6 \times 10^{-6} \mathrm{~mol} \mathrm{~L}^{-1}$ respectively. A plot of between $\log \mathrm{Rp}$ and $\log$ [AN] (Figure 7) is linear, the slope of which gives the relationship : Equation (3)

$$
R_{p} \alpha[A N]^{1.2}
$$

The deviation in the values of initiator, Sty, VA and AN

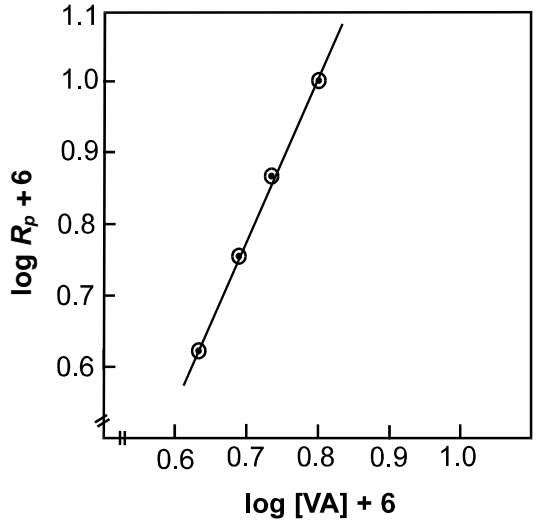

Figure 6. Plot of $\log R_{p}$ versus $\log$ [VA].

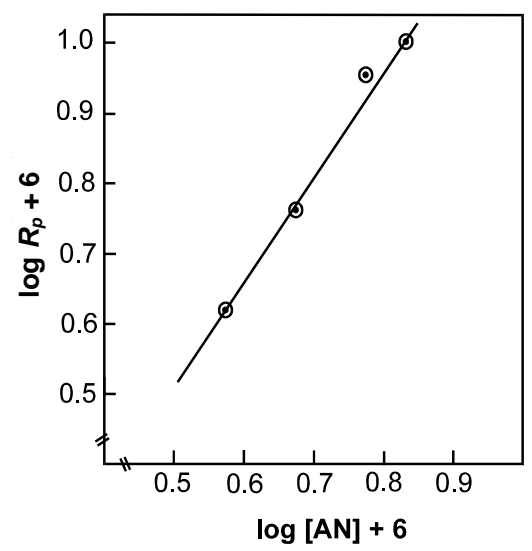

Figure 7. Plot of $\log R_{p}$ versus $\log$ [AN].

exponents can be explained on the basis of primary radical termination [18] and degradative chain transfer [19].

Primary radical termination was explained by the expression given by Deb and Meyerhoff. This expression has been frequently used for terpolymerization [20]. Equation (4)

$$
\log \frac{R_{p}^{2}}{[\mathrm{I}][\mathrm{M}]^{2}}=\log \frac{2 f_{k} k_{d} k_{p}^{2}}{k_{t}}-0.864 \frac{k_{p r t} R_{p}}{k_{i} k_{p}[\mathrm{M}]^{2}}
$$


where $f_{k}$ represents the fraction of free radical to initiating chain growth, $k_{d}$ is the initiator decomposition rate constant, $k_{p}$ is the propagation rate constant, and $k_{p r t}$ is the primary radical termination constant, $[\mathrm{M}]$ is the monomer concentration.

The plot (Figure 8) of the left-hand side of the aforementioned equation versus $R_{p} /[\mathrm{M}] 2$ gave a negative slope, indicating significant primary radical termination.

The equation by Ghosh and Mitra [21] was used to examine degradative chain transfer reactions as follows: Equation (5)

$$
\log \frac{R_{p}^{2}}{[\mathrm{I}][\mathrm{M}]^{2}}=\log \frac{2 f_{k} k_{d} k_{p}^{2}}{k_{t}}-0.434 \frac{k_{p}^{2} k_{r t I}}{k_{t} k_{i I} k_{p}} C_{1} \frac{[\mathrm{I}]}{[\mathrm{M}]}
$$

where $\mathrm{CI}$ is the initiator transfer constant, $k_{r t I}$ is the rate constant of degradative chain transfer to initiator and $k_{i I}$ is the initiator rate constant.

A plot (Figure 9) of the left hand side of the preceding equation versus $[\mathrm{I}] /[\mathrm{M}]$ gave a negative slope. The deviation in the exponent value of initiator and monomers in the present system appears due to both primary radical termination and degradative chain transfer.

\section{Effect of temperature:}

The polymerization runs were carried out at $55^{\circ} \mathrm{C}$, increases with increase in temperature. The energy of acti-

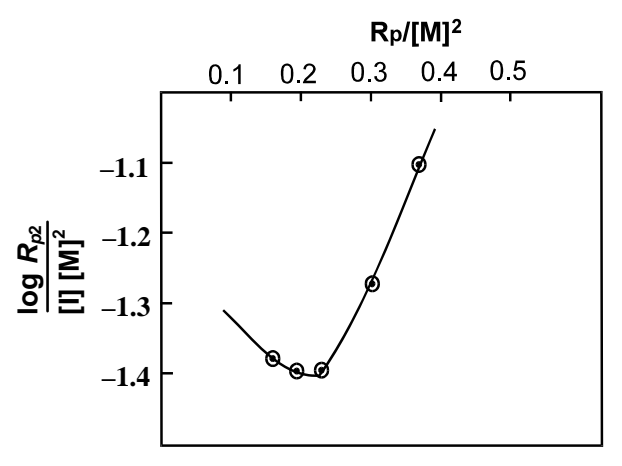

Figure 8. Plot of $R_{p}^{2} /[\mathrm{I}][\mathrm{M}]^{2}$ versus $R_{p} /[\mathrm{M}]^{2}$.

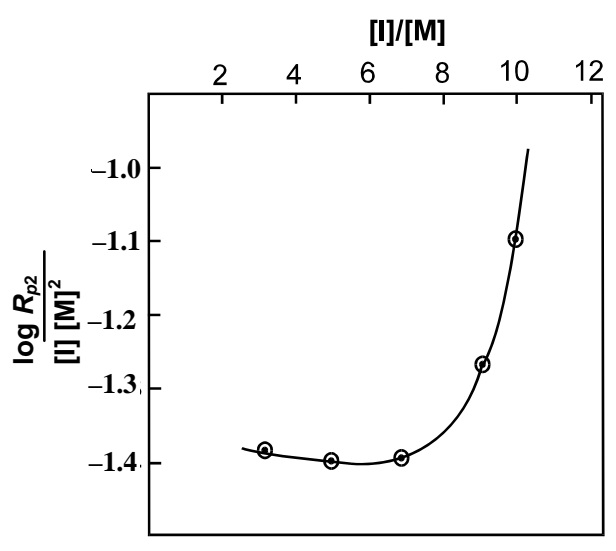

Figure 9. Plot of $R_{p}{ }^{2} /[\mathrm{I}][\mathrm{M}]^{2}$ versus [I]/[M]. vation was calculated from the Arrhenius plot (Figure 10) as $46 \mathrm{~kJ} / \mathrm{mol}$

Characterization of the terpolymer:

FTIR: The FTIR (Figure 11) spectra[22] of the terpolymer exhibit characteristic absorption band at 3430 $\mathrm{cm}^{-1}, 1598 \mathrm{~cm}^{-1}, 2362 \mathrm{~cm}^{-1}$ of phenyl group, acetoxy group and nitrile group respectively. This confirms the incorporation of all the three monomers in the terpolymer.

1H-NMR: The 1H-NMR spectra[22] shows (Figure 12) a multiplet at 7.6 to $7.9 \delta$ ppm due to phenyl protons of styrene and the peak at $2.1 \delta \mathrm{ppm}$ to the acetoxy protons of vinyl acetate characteristic chemical shift values of the methane and methylene protons of polymer backbone chain were at $1.0-3.8 \delta \mathrm{ppm}$.

13C-NMR: The ${ }^{13} \mathrm{C}-\mathrm{NMR}$ spectra (Figure 13) of the terpolymer showed a peak at 175 due to the carbonyl carbon of vinyl acetate $137 \delta \mathrm{ppm}$ at aromatic carbon resonance of the styrene and at $128 \mathrm{ppm}$ due to nitrile carbon of acrylonitrile also confirms incorporation of all the three monomers in the polymer.

GPC: The GPC Parameters are presented in Table 3. It appears from the molecular data of the terpolymer that with increase in the initiator concentration the $\left(\bar{M}_{v}\right)$ viscosity average molecular weight decreases with the increase in initiator concentration because of increased number of radicals in the medium.

\section{DSC Analysis:}

The DSC curve (Figure 14) indicates that the glass transition temperature $\left(T_{g}\right)$ of (Sty-co-VA-co-AN) is $149.5^{\circ} \mathrm{C}$. The transition of melting range originate from $377^{\circ} \mathrm{C}$ and the terpolymer is decomposed completely at $404^{\circ} \mathrm{C}$. The $T_{g}$ evaluated from the experimental data is in excellent agreement with the calculated one.

The calculated $T_{g}$ from the Fox equation [23] Equation (6) below is $154^{\circ} \mathrm{C}$

$$
\frac{100}{T_{g}}=\frac{W_{1}}{T_{g 1}}+\frac{W_{2}}{T_{g 2}}+\frac{W_{3}}{T_{g 3}}
$$

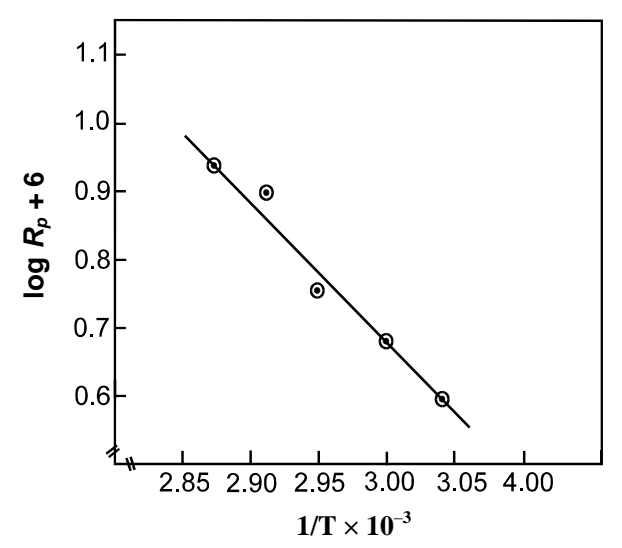

Figure 10. Arrhenius plot of $\log R_{p}$ versus $1 / \mathrm{T} \times 10^{3}$. 


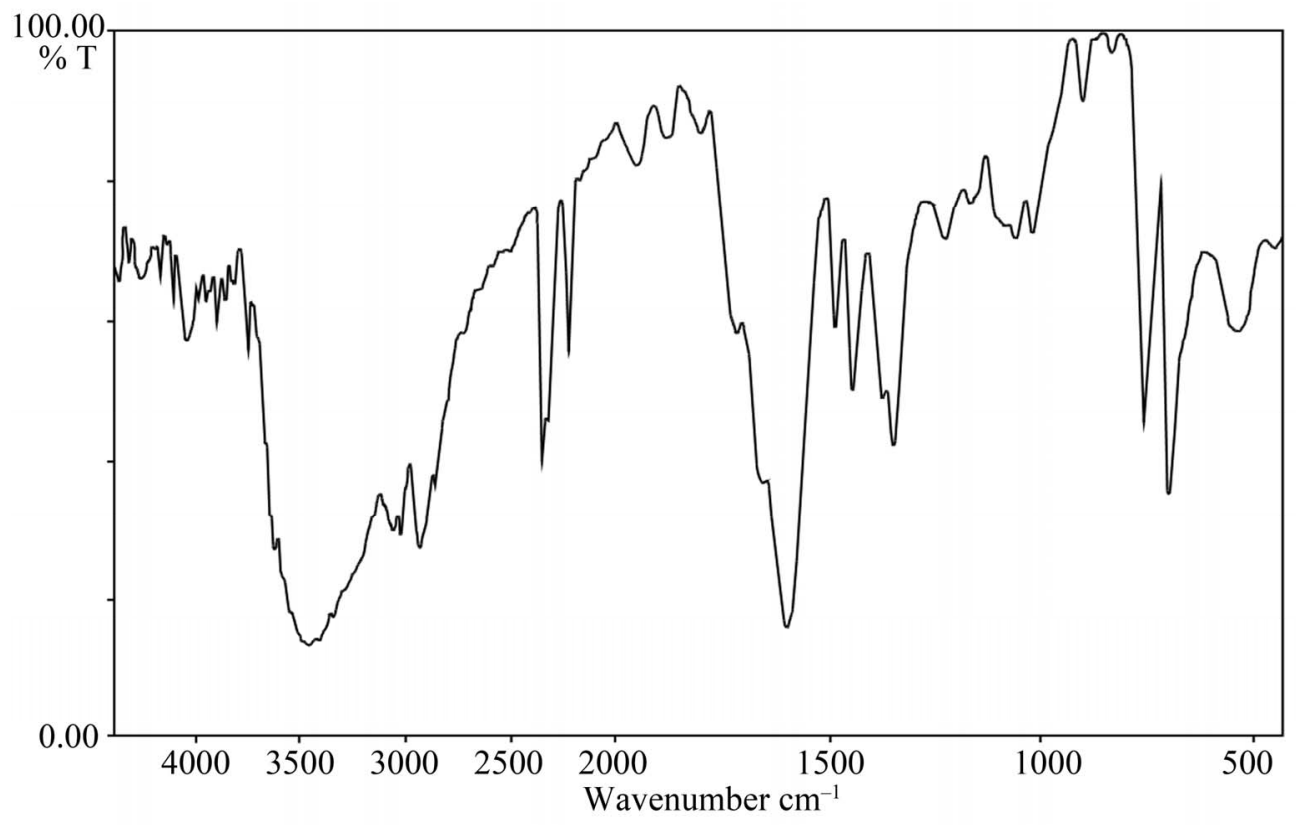

Figure 11. FTIR spectral analysis of terpolymer of sample No. 3.

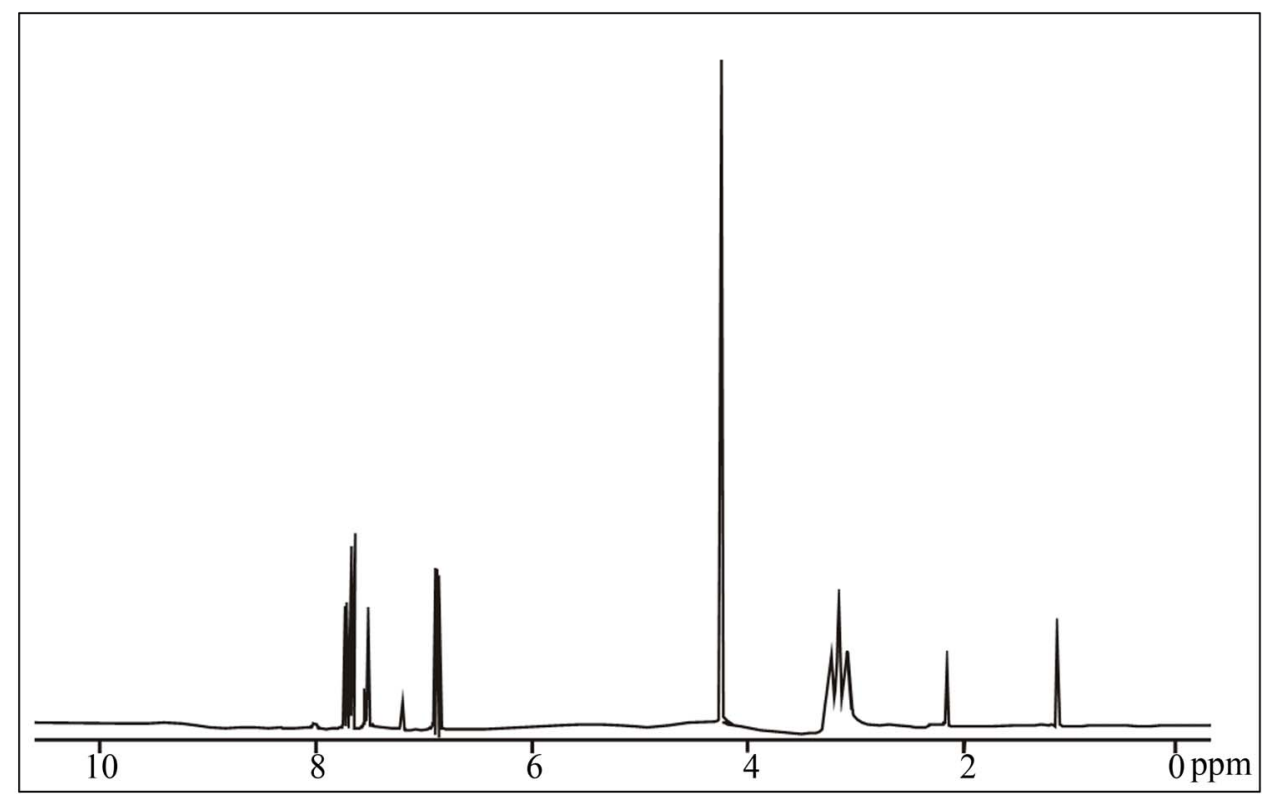

Figure 12. ${ }^{1} \mathrm{H}$-NMR spectral analysis of terpolymer sample No. 3

Table 3. G.P.C Parameters of terpolymer (p-NBTPY variation).

\begin{tabular}{cccccccccc}
\hline $\begin{array}{c}\text { Sample } \\
\text { No. }\end{array}$ & $\begin{array}{c}\text { Numerical } \\
\text { average }\end{array}$ & $\begin{array}{c}\text { Weight } \\
\text { Average }\end{array}$ & Z average & $\begin{array}{c}\text { Viscosity } \\
\text { average }\end{array}$ & $\eta_{[i n t]}$ & $\frac{M_{w}}{M_{n}}$ & $\frac{M_{z}}{M_{n}}$ & $\frac{M_{v}}{M_{n}}$ & $\frac{M_{z}}{M_{w}}$ \\
\hline 1. & 49391 & 321579 & 838082 & 778997 & 0.00058 & 6.5 & 16.9 & 2.4 & 2.6 \\
3. & 18613 & 43925 & 396191 & 363988 & 0.00046 & 7.73 & 21.28 & 2.52 & 2.75 \\
5. & 13735 & 38404 & 74420 & 73964 & 0.00028 & 2.79 & 5.41 & 1.92 & 1.93 \\
\hline
\end{tabular}




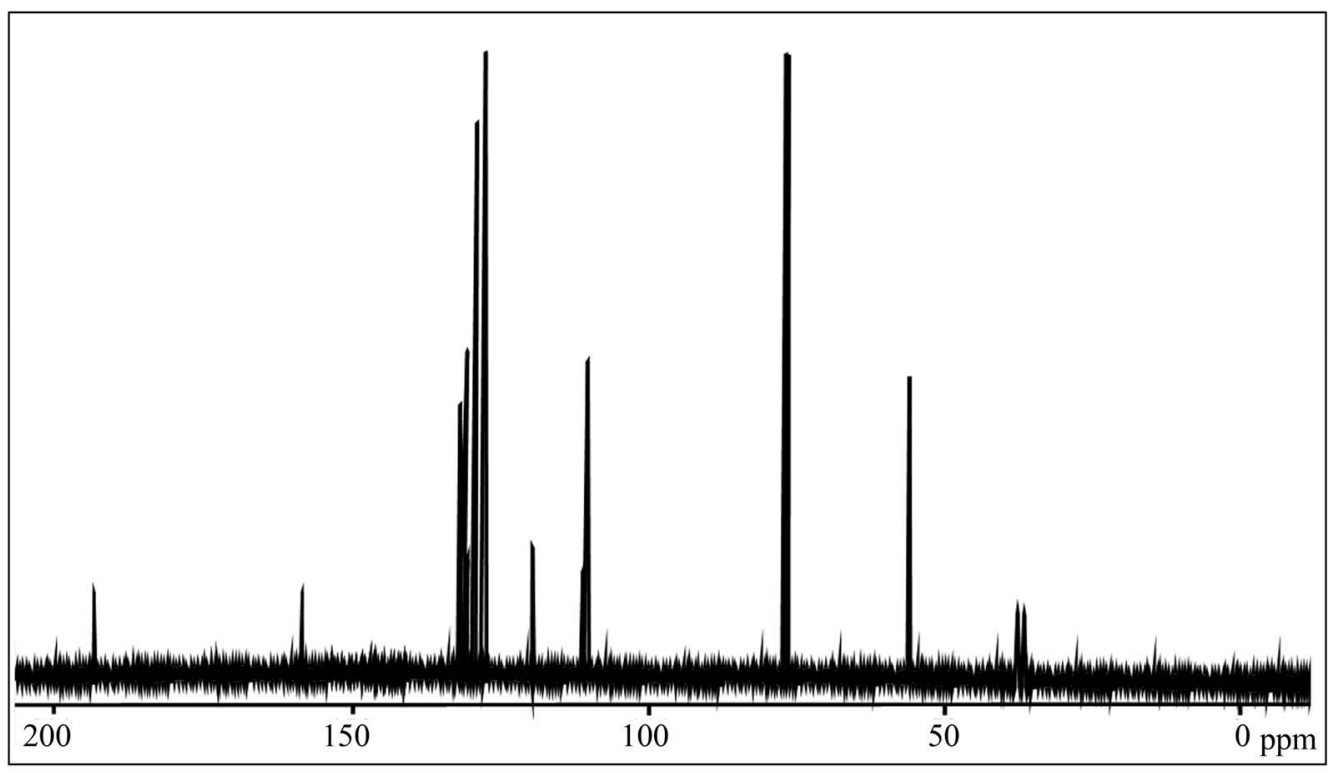

Figure $13 .{ }^{13} \mathrm{C}$-NMR spectral analysis of terpolymer sample No. 3.

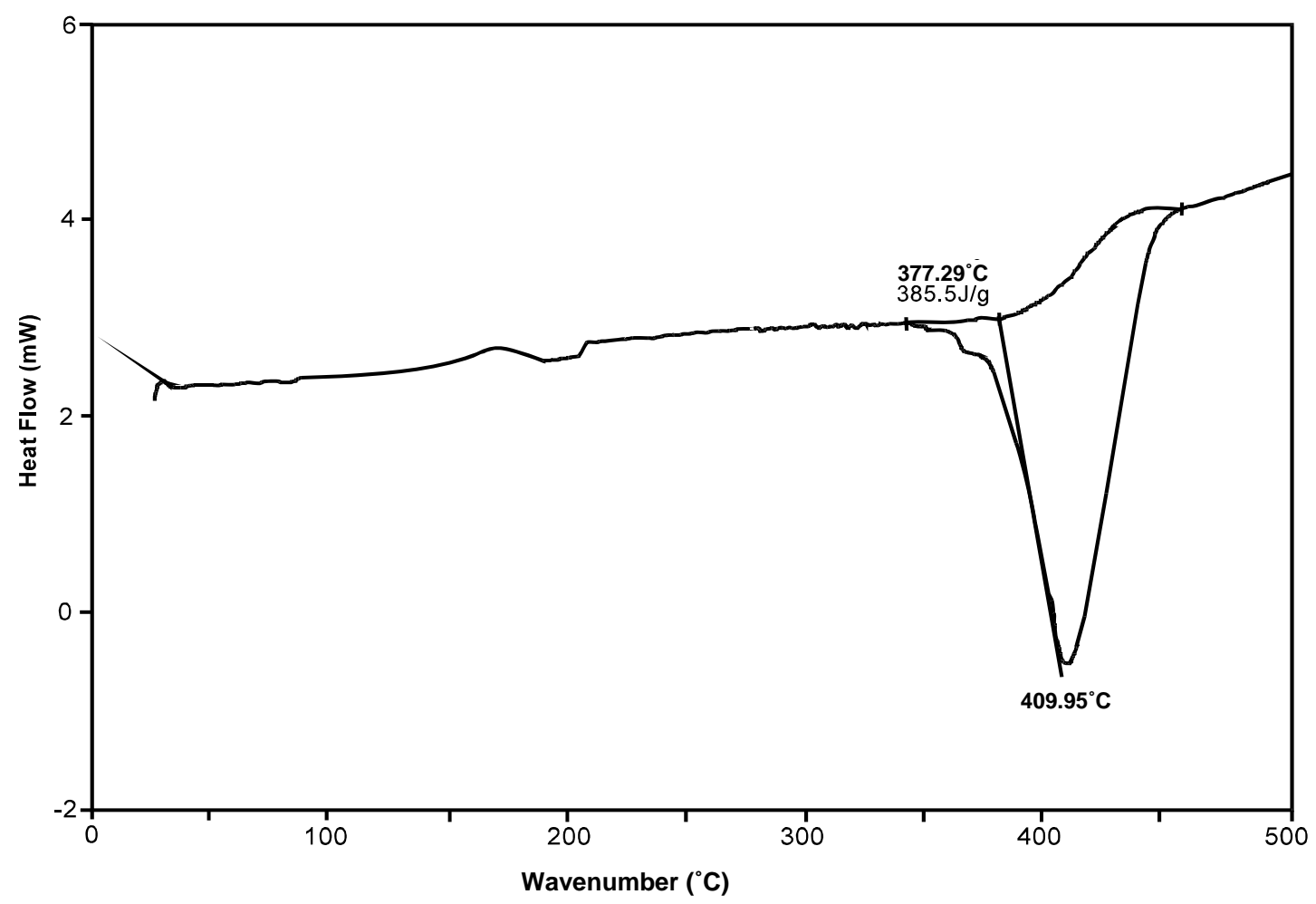

Figure 14. DSC curve of terpolymer sample No. 3.

where the composition for [Sty] $W_{1}=25, T_{g}=\left[100^{\circ} \mathrm{C}\right]$ [24], [AN] $W_{2}=50, T_{g}=\left[97^{\circ} \mathrm{C}\right][23],[\mathrm{VA}] W_{3}=25, T_{g}$ $=\left[32^{\circ} \mathrm{C}\right][26]$. Nevertheless, the observation of a single $T_{g}$ and a $T_{g}$ close to that predicated by equation indicates complete mixing during free radical polymerization.

SEM: The terpolymer obtained was phosphorus free. The absence of phosphorus is confirmed by a qualitative test using concentrate nitric acid and ammonium molybdate where yellow precipitate was not obtained. SEM report (Figure 15) also indicates the absence of phosphorus in the polymer.

\section{Reactivity Ratio:}

The relative area of peaks at $7.6-7.9 \delta$. ppm (due to phenyl protons) of [Sty] and a peak at $2.1 \delta \mathrm{ppm}$ (due to 


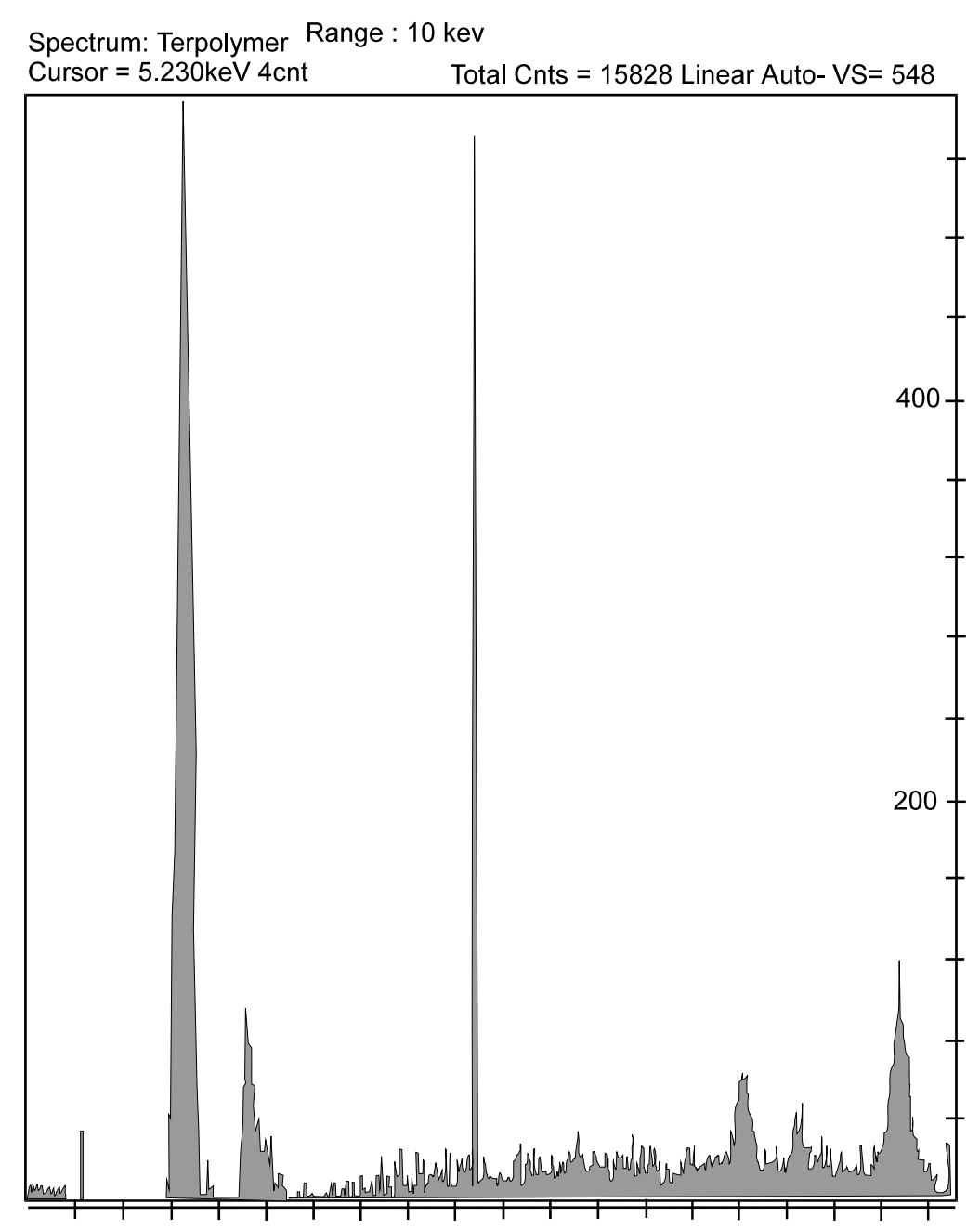

Figure 15. SEM report of terpolymer sample No. 3.

acetoxy protons) of vinyl acetate, acrylonitrile content from the nitrogen percentage are used to calculate the reactivity ratios. The composition of terpolymer are shown in Table 4.

The Kelen-Tüdos [27] approach is used for evaluation of reactivity ratios, monomer according to taking Sty and $\mathrm{VA}$ as $r_{1}$ and $\mathrm{AN}$ as $r_{2}$. The equations Equation (7) are:

$$
\eta=r_{1} \xi-\frac{r_{2}(1-\xi)}{\alpha}
$$

where $\eta=\frac{G}{(\alpha+H)}$ and $\xi=\frac{H}{\alpha+H}$

the transformed variables $\mathrm{G}$ and $\mathrm{H}$ are given by

$$
\begin{gathered}
G=\frac{\left[\mathrm{M}_{1}\right] /\left[\mathrm{M}_{2}\right]\left[\mathrm{d}\left[\mathrm{M}_{1}\right] / \mathrm{d}\left[\mathrm{M}_{2}\right]-1\right]}{\mathrm{d}\left[\mathrm{M}_{1}\right] / \mathrm{d}\left[\mathrm{M}_{2}\right]} \\
H=\frac{\left[\mathrm{M}_{1}\right] /\left[\mathrm{M}_{2}\right]^{2}}{\mathrm{~d}\left[\mathrm{M}_{1}\right] / \mathrm{d}\left[\mathrm{M}_{2}\right]}
\end{gathered}
$$

The parameter is calculated by the square root of the product of the lowest and highest values of $\mathrm{H}$ for the copolymerization series. The graphical evaluation (Figure 16) for Sty and VA yield values of $r_{1}=0.1$ and $\mathrm{AN}$ yields value of $r_{2}=0.005$. The product of $r_{1} r_{2}$ is nearly zero, which is the sign of alternating terpolymerization.

\section{Mechanism}

P-NBTPY ylide is considered to be the resonance hybrid of the following structure. (see Machanism)

As reported in the literature [11], the initiator undergoes bond fission between the heteroatom and phenyl group on irradiation by a high pressure mercury lamp and the phenyl radicals produced participate in the initiation of the polymerization. From structural similarity, it seems that p-NBTPY also undergoes similar fission and phenyl radical participates in the initiation. This was confirmed by the ESR results (Figure 17) that the ylide dissociates, yielding a phenyl free radical. It also confirms the free radical mode of polymerization giving the value of gyromagnetic ratio " $g$ " as 2.11 . It matches well 


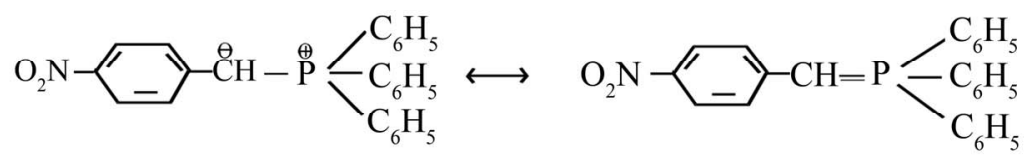

\section{Mechanism}

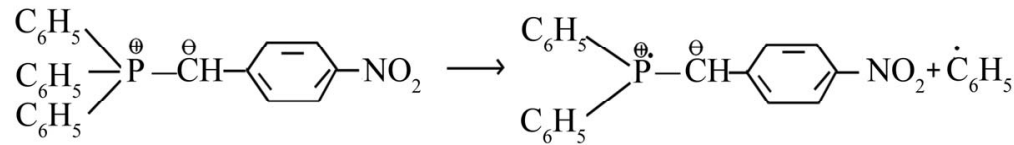

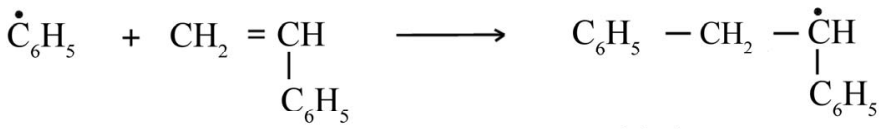

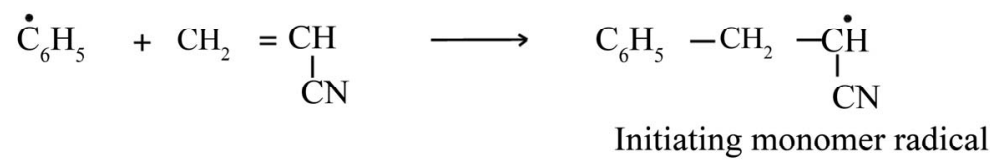

$$
\dot{\mathrm{C}}_{6} \mathrm{H}_{5}+\mathrm{CH}_{2}=\underset{\mathrm{OCOCH}_{3}}{\mathrm{CH}} \longrightarrow \mathrm{C}_{6} \mathrm{H}_{5}-\mathrm{CH}_{2}-\underset{\mathrm{OCOCH}}{\stackrel{\mathrm{C}}{\mathrm{H}}}
$$

Initiating monomer radical

Initiation

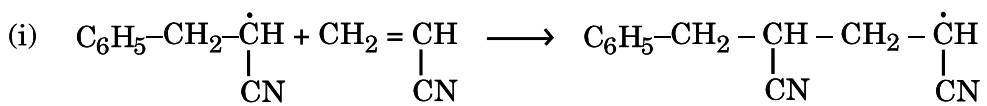

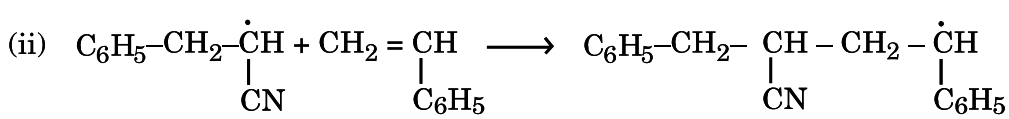

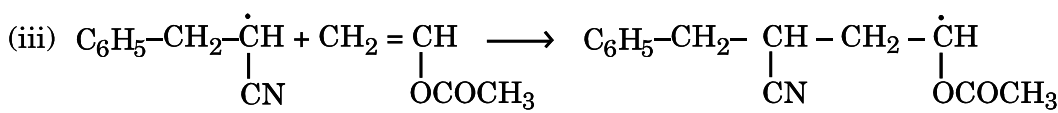

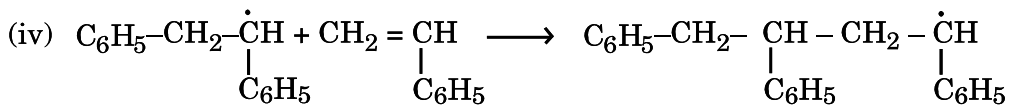

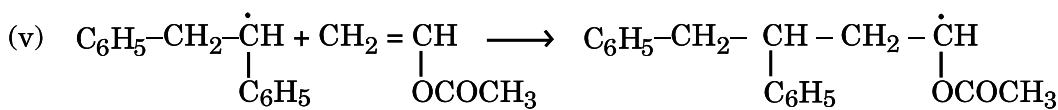

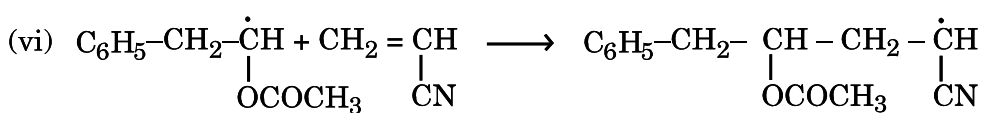

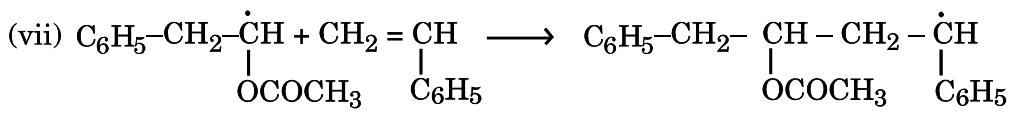

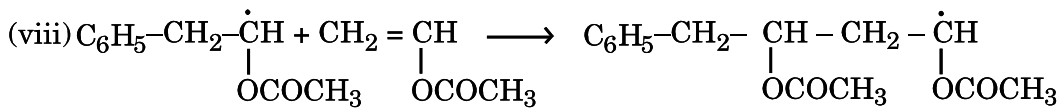

Propagation 


$$
\begin{aligned}
& m \mathrm{nCH}_{2}-\underset{\mathrm{CN}}{\stackrel{\dot{\mathrm{C}} \mathrm{H}}{l}}+m \mathrm{nCH}_{2}-\underset{\mathrm{C}_{6} \mathrm{H}_{5}}{\stackrel{\dot{\mathrm{C}}}{I}}+m n \mathrm{nCH}_{2}-\underset{\mathrm{OCOCH}_{3}}{\stackrel{\dot{\mathrm{C}} \mathrm{H}}{\longrightarrow}} \longrightarrow \\
& {\left[\begin{array}{ccc}
\mathrm{CH}_{2}-\underset{\mathrm{CH}}{\mathrm{CH}}-\mathrm{CH}_{2}-\underset{\mathrm{CH}}{\mathrm{C}}-\mathrm{CH}_{2}-\underset{\mathrm{I}}{\mathrm{CH}} \\
\mathrm{CN} & \mathrm{C}_{6} \mathrm{H}_{5} & \mathrm{OCOCH}_{3}
\end{array}\right]_{\mathrm{n}}}
\end{aligned}
$$

\section{Termination}

\begin{tabular}{|c|c|c|c|c|c|c|}
\hline \multirow[b]{2}{*}{ Sample No. } & \multirow{2}{*}{$\begin{array}{l}\text { Monomer feed } \\
\text { (F) }\end{array}$} & \multirow{2}{*}{$\begin{array}{l}\text { Polymer feed } \\
\text { (f) }\end{array}$} & \multirow[b]{2}{*}{$\%$ Conversion } & \multicolumn{3}{|c|}{ Monomer composition } \\
\hline & & & & $\begin{array}{l}\text { Mole fraction } \\
\text { of }[\text { Sty }]^{*}\end{array}$ & $\begin{array}{l}\text { Mole fraction of } \\
{\left[\text { [VA] }^{* *}\right.}\end{array}$ & $\begin{array}{l}\text { Mole fraction of } \\
{[\mathrm{AN}]^{* * *}}\end{array}$ \\
\hline 03 & 1.43 & 1.4 & 10.6 & 1.44 & 1.44 & 2.01 \\
\hline 06 & 2.00 & 1.9 & 7.02 & 0.28 & 1.44 & 2.01 \\
\hline 09 & 0.85 & 0.98 & 15.6 & 2.59 & 1.44 & 2.01 \\
\hline 10 & 0.71 & 0.37 & 9.1 & 1.44 & 0.72 & 2.01 \\
\hline 12 & 2.88 & 2.31 & 14.3 & 1.44 & 2.88 & 2.01 \\
\hline 13 & 2.14 & 1.8 & 5.6 & 1.44 & 1.44 & 1.00 \\
\hline 15 & 1.074 & 0.96 & 15.7 & 1.44 & 1.44 & 4.02 \\
\hline
\end{tabular}

Table4. Composition of terpolymer. sis; $[\mathrm{p}-\mathrm{NBTPY}]=33.6 \times 10^{-6} \mathrm{~mol} \mathrm{~L}{ }^{-1}$, temperature $=65^{\circ} \mathrm{C} \pm 1^{\circ} \mathrm{C}$, Time $=150 \mathrm{~min}$.

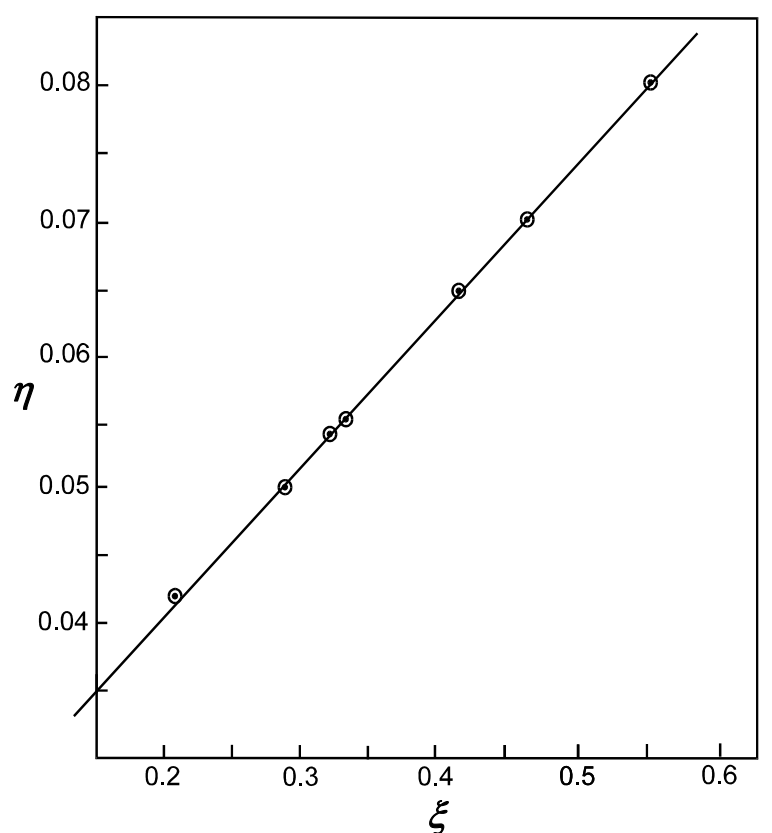

Figure 16. Kelen-Tüdos plot of terpolymer for determination of reactivity ratio.

with the value given for free radical polymerization. The spectra shows[28] six hyperfine lines and hyperfine con-stant as $3.74(\mathrm{G})$. The free radical mode of polymerization was also confirmed by the inhibitory effect of hydroquinone on the rate of polymerization.

\section{Conclusions}

p-nitrobenzyltriphenyl phosphonium ylide (p-NBTPY)is

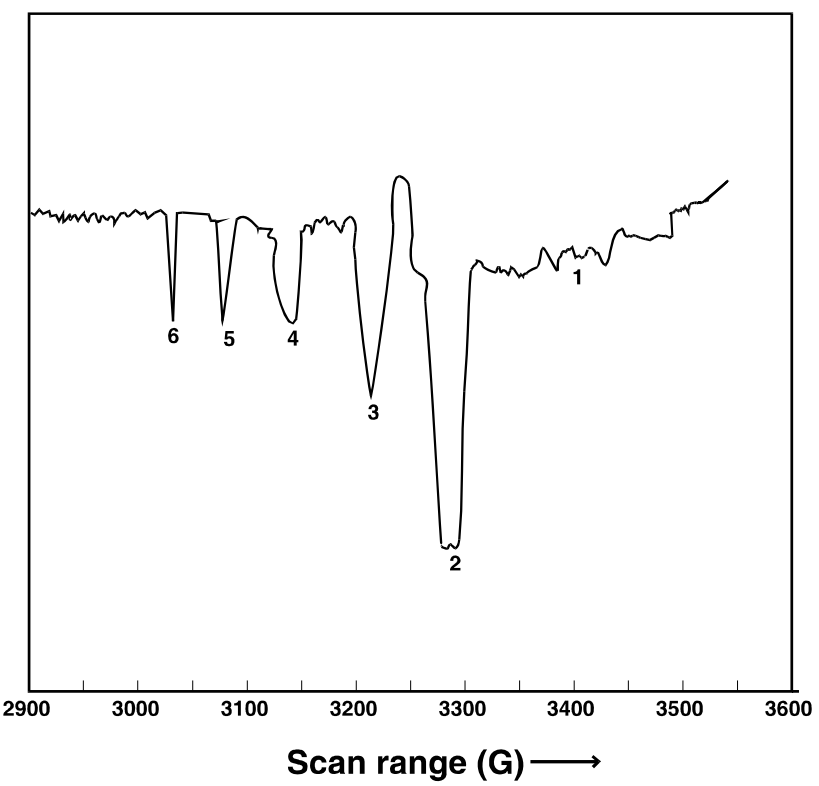

Figure 17. ESR spectrum of terpolymer sample No. 3.

capable of initiating the polymerization of (Sty-co-ANco-VA) in dioxane solution giving in alternating terpolymer without using Lewis acid. The formation of terpolymer is confirmed by the FTIR spectra showing bands at $3030 \mathrm{~cm}^{-1}, 1598 \mathrm{~cm}^{-1}$, and $2362 \mathrm{~cm}^{-1}$, confirming the presence of phenyl, acetoxy and nitrile group respectively. SEM confirms the polymer to be phosphorus free. E.S.R. spectra confirms phenyl radical responsible for initiation. The DSC studies evidenced the glass transition temperature of terpolymers as $149.5^{\circ} \mathrm{C}$. 


\section{Acknowledgements}

The authors are grateful to the Dr. Meeta Jamal, Principal Dayanand Girls College, Kanpur, India for providing necessary facilities, Dr. A. Varshney is thankful to U.G.C. New Delhi for sanctioning the project entitled "Polymerization of vinyl monomers using ylide and metal ylide complexes as new radical initiators (F.12-5/2004 (SR)).

One of the author (K.P.) is thankful to the Under Secretary, Uttar Pradesh Shasan, India for sanctioning the study leave to conduct this research.

\section{References}

[1] P. Shukla and A. K. Srivastava, "Terpolmerization of Styrene, Acrylonitrile and Chromium Acrylate: Synthesis, and Properties," Polymer, Vol. 35, No. 21, 1994, pp. 4665-4668. doi:10.1016/0032-3861(94)90819-2

[2] P. Shukla and A. K. Srivastava, "Synthesis, Characterization and Kinetic Studies of Styrene-Methylmethacrylate-Acrylonitrile Terpolymer Initiated by Styrene-Arsenic Sulphide Complex," Macromolecular Reports, Vol. 31, No. 3-4, 1994, pp. 315-325.

[3] P. Pandey and A. K. Srivastava, "Synthesis and Characterization of Optically Active and Functional Terpolymer of Citronellol, Styrene and Methylmethacrylate: A Kinetic Study," Advance in Polymer Technology, Vol. 21, No. 1, 2002, pp. 59-64.

[4] P. Shukla and A. K. Srivastava, " $p$-Acetyl Benzylidiene Triphenylarsonium Initiated Coplymerization of Citronellol and Styrene," Polymer International, Vol. 41, No. 4, 1996, pp. 407-412.

doi:10.1002/(SICI)1097-0126(199612)41:4<407::AID-PI 629>3.3.CO;2-S

[5] Z. Q. Hu and Z. C. Zhang, “'Gradient' Polymer Prepared by Complex-Radical Terpolymerization of Styrene, Maleic Anhydride, and $N$-Vinyl Pyrolidone via $\gamma$-Ray Irradiation by Use of a Raft Process: Synthesis, Mechanism, and Characterization," Vol. 39, No. 4, 2006, pp. 1384-1390. doi:10.1021/ma051997z

[6] C. Zhou, M. A. Hillmyer and T. P. Lodge, "Micellization and Micellar Aggregation of Poly(ethylene-alt-propylene)- $b$-poly(ethylene oxide)- $b$-poly( $N$-isopropylacrylamide) Triblock," Macromolecules, Vol. 44, No. 6, 2011, pp. 1635-1641. doi:10.1021/ma102786q

[7] N. A. Bokach, S. I. Selivanov, V. Y. Kukushkin, J. Vicente, M. Haukka and A. J. L. Pombeiro, "Synthesis of the First Family of Platinum (IV) Complexes with Phosphorus Ylide Ligands," Organometallics, Vol. 21, No. 18, 2002, pp. 3744-3748.

[8] A. K. Srivastava and A. K. Chaurasia, "Kinetics and Mechanism of Polymerization of Methyl Methacrylate Initiated by Stibonium Ylide," Journal of Chemical Sciences, Vol. 116, No. 1, 2004, pp.55-59.

doi:10.1007/BF02708214
[9] R. Vasistha, P. Kumar, S. K. Awasthi, U. Bhatnagar and A. K., Srivastava, "Retarding Effect of Nitrogen Ylide for the Polymerization of $N$-Vinyl Pyrrolidone," Colloid and Polymer Science, Vol. 268, No. 7, 1990, pp. 645-648. doi:10.1007/BF01410406

[10] A. K. Shukla, S. Saini, P. Kumar, J. S. P. Rai and A. K. Srivastava, "Studies on Polymerization of Vinyl Acetate Using Ylide as an Initiator," Journal of Polymer Science Part A: Polymer Chemistry, Vol. 27, No. 3, 1989, pp. 807-815. doi:10.1002/pola.1989.080270306

[11] K. Prajapati and A. Varshney, "Free Radical Polymerization of Styrene with $p$-Nitrobenzyl Triphenyl Phosphonium Ylide as an Initiator," Journal of Polymer Science Part A: Polymer Chemistry, Vol. 43, No. 24, 2005, pp. 6524-6533. doi:10.1002/pola.20708

[12] K. Prajapati and A. Varshney, "Free Radical Polymerization of Methylmethacrylate Using $p$-Nitrobenzyltriphenyl Phosphonium Ylide as Novel Initiator," Journal of Polymer Research, Vol. 13, No. 2, 2006, pp. 97-105. doi:10.1007/s10965-005-9011-0

[13] K. Prajapati and A. Varshney, "Phosphorous Ylide (p-NBTPY) as New Initiator in Polymerization of Ethyl acrylate: A Kinetic Study and Characterization," Asian Journal of Chemistry, Vol. 23, No. 6, 2011, pp. 2361-2368.

[14] G. D. Gilheany, "Ylides, PhosphoniumNo d Orbitals but Walsh Diagrams and Maybe Banana Bonds: Chemical Bonding in Phosphines, Phosphine Oxides, and Phosphonium Ylides," Chemical Reviews, Vol. 94, No. 5, 1994, pp. 1339-1374. doi:10.1021/cr00029a008

[15] K. Prajapati and A. Varshney, " $p$-Nitrobenzyltriphenyl Phosphonium Ylide-Initiated Radical Terpolmerization of Styrene, Methyl Methacrylate and Acrylonitrile: Synthesis, Characterization and Properties," Polymer International, Vol. 56, No. 1, 2007, pp. 32-40. doi:10.1002/pi.2104

[16] A. I. Vogel, "A Text Book of Practical Organic Chemistry," 5th Edition, Longman, London, 1989.

[17] S. Saini, R. Vasishtha, P. Shukla and A. K. Srivastava, "Ylide-Initiated Polymerization of 4-Vinylpyridine," Macromolecules, Vol. 22, No. 3, 1989, pp. 1025-1027. doi:10.1021/ma00193a004

[18] P. C. Deb and G. Meyerhoff, "Primary Radical Termination in Polymerization: Evaluation of the Termination Constant," European Polymer Journal, Vol. 10, No. 8, 1974, pp. 709-715. doi:10.1016/0014-3057(74)90184-0

[19] P. C. Deb, "Non-Ideal Polymerization. Treatment of Non-Ideality Due to Primary Radical Termination and Degradative Chain Transfer," European Polymer Journal, Vol. 11, No. 1, 1975, pp. 31-36. doi:10.1016/0014-3057(75)90171-8

[20] P. Kumar, D. Narayan and A. K. Srivastava, "Synthesis Characterization and Kinetics of Terpolymerization of Acrylonitrile, $N$-Vinyl Pyrrolidone and Styrene," Polymer International, Vol. 31, No. 3, 1993, pp. 221-236. 
doi:10.1002/pi.4990310302

[21] P. Ghosh and P. S. Mitra, "Novel Solvent Effects in the Photopolymerization of Methyl Methacrylate by Use of Quinoline-Bromine Charge-Transfer Complex as Photoinitiator," Journal of Polymer Science: Polymer Chemical Edition, Vol. 15, No. 7, 1977, pp. 1743-1758.

[22] R. M.Silverstein and F. X. Webster, "Spectrophotometric Identification of Organic Compounds," 6th Edition, Wiley, New York, 2001.

[23] A. A. Mahmoud, D. P. Thomas, H. B. Malcoln and C. F. Y. Daniel, "Copolymerization Involving $n$-Vinyl-2-pyrolidone," Vol. 26, 1985, pp.1869-1874.

[24] J. Brandrup and E. H. Immergut, "Polymer Handbook," 2nd Edition, III, 154, Wiley, New York, 1974.
[25] J. Brandrup and E. H. Immergut, "Polymer Handbook," 2nd Edition, III, 148, Wiley, New York, 1974.

[26] J. Brandrup and E. H. Immergut, "Polymer Handbook," 2nd Edition, III, 151, Wiley, New York, 1974.

[27] T. Kelen and F. Tüdos, "Analysis of the Linear Methods for Determining Copolymerization Reactivity Ratios. I. A New Improved Linear Graphic Method," Journal of Macromolecular Science: Part A-Chemistry, Vol. 9, No. 1, 1975, pp. 1-27. doi:10.1080/00222337508068644

[28] A. K. Srivastava and M. Kaur, "Photopolymerization of Styrene Initiated by Triphenyl Bismuthonium Ylide," Macromolecular Rapid Communications, Vol. 21, No. 6, 2000, pp. 291-295. doi:10.1002/(SICI)1521-3927(20000301)21:6<291::AIDMARC291>3.0.CO;2-F

\section{Analysis Report}

\section{General Conditions}

\begin{tabular}{|c|c|c|c|c|c|c|c|c|}
\hline \multicolumn{4}{|l|}{ Result File } & $:$ & Terpolymer & & & \\
\hline \multicolumn{4}{|c|}{ File Version } & $:$ & 1 & & & \\
\hline \multicolumn{4}{|c|}{ Background Method } & : & Auto & & & \\
\hline \multicolumn{4}{|c|}{ Decon Method } & : & Gaussian & & & \\
\hline \multicolumn{4}{|c|}{ Decon ChiSquared } & : & 11.18 & & & \\
\hline \multicolumn{4}{|c|}{ Analysis Date } & : & 19-March-2005 & & & \\
\hline \multicolumn{4}{|l|}{ Microscope } & : & SEM & & & \\
\hline \multicolumn{4}{|l|}{ Comments } & : & & & & \\
\hline \multicolumn{9}{|c|}{ A. ANALYSIS CONDITIONS } \\
\hline \multicolumn{4}{|c|}{ Quant. Method } & : & XPP/ASAP & & & \\
\hline \multicolumn{4}{|c|}{ Acquire Time } & : & $50 \mathrm{sec}$ & & & \\
\hline \multicolumn{4}{|c|}{ Nationalization Factor } & $:$ & 100.00 & & & \\
\hline \multicolumn{9}{|c|}{ B. SAMPLE CONDITIONS } \\
\hline \multicolumn{4}{|c|}{$\mathrm{Kv}$} & : & 15.0 & & & \\
\hline \multicolumn{4}{|l|}{ Beam Current } & : & 137.9 picoAmps & & & \\
\hline \multicolumn{4}{|c|}{ Working Distance } & : & $25.0 \mathrm{~mm}$ & & & \\
\hline \multicolumn{4}{|c|}{ Tilt Angle } & : & 0.0 Degrees & & & \\
\hline \multicolumn{4}{|c|}{ Take Off Angle } & : & 35.0 Degrees & & & \\
\hline \multicolumn{4}{|c|}{ Solid Angle Beam Current } & $:$ & 1.2 & & & \\
\hline Element & Line & Weight $\%$ & K-Ratio & & Decon & Region & Cnts/s & Atomic\% $\%$ \\
\hline $\mathrm{P}$ & $\mathrm{Ka}$ & 0.00 & 0.0000 & & $0.000-0$ & & 0.00 & 0.00 \\
\hline $\mathrm{Cu}$ & $\mathrm{Ka}$ & 4.03 & 0.0528 & & $7.660-8.430$ & & 25.99 & 10.77 \\
\hline $\mathrm{Pd}$ & $\mathrm{La}$ & 1.30 & 0.0090 & & $2.640-3.040$ & & 16.47 & 2.08 \\
\hline $\mathrm{Au}$ & $\mathrm{La}$ & 91.54 & 0.8896 & & $9.220-10.13$ & & 41.58 & 79.00 \\
\hline $\mathrm{Zn}$ & $\mathrm{Ka}$ & 3.14 & 0.0429 & & $8.230-9.030$ & & 15.51 & 8.15 \\
\hline Total & & 100.01 & & & & & & \\
\hline
\end{tabular}

